\title{
INNOVATIVE MODELING METHOD IN TECHNICAL TRAINING OF HIGH JUMPERS
}

\author{
Innovative high jump technique modeling
}

\author{
ILYA Y. KRIVETSKIY, GRIGORIY I. POPOV \\ Russian State University of Physical Education, Sport, Youth and Tourism in Moscow \\ Department of Natural Sciences
}

Mailing address: Ilya Y. Krivetskiy, Russian State University of Physical Education, Sport, Youth and Tourism, Department of Natural Sciences, Sirenevyi Boulevard 4, Moscow, Russia, tel.: +7 9265824748, fax + 7 4991665471, e-mail: hijumper@mail.ru

\begin{abstract}
Introduction. This essay introduces an innovative high jump technique modeling method that uses a cascaded fuzzy neural network. An interactive system for the prediction of the success of a high jump has been designed based on this method and it allows the creation of an individual model for highly skilled athletes to control the jumper's technical training. Material and methods. The research material included a video recording of 92 high jumps and analysis by 48 kinematic characteristics. The result allowed the fine tuning of the cascaded fuzzy neural network model in order to analyse successful and failed jumps. Results and conclusions. We have developed the interactive system based on the analysis of kinematic characteristics of the high jump and this allows individual performance models to be tailored for elite athletes. With the help of this instrument, which takes into account the individual biomechanical features of an athlete's jumping style, we can analyze all stages of a jump in detail, improve the technique through the targeted correction of specific motions and achieve the optimal combination of kinematic values for the best possible result.
\end{abstract}

Key words: high jump, biomechanics, modeling, cascaded fuzzy neural network

\section{Introduction}

Incorporating modern information technologies into the training process is a promising way to advance sports management systems. Many devices are currently being used to improve technical training conditions for athletes. Nevertheless, an educational oversight of sports devices does not guarantee the optimal level of an athlete's technical training management [1]. A potentially more productive approach to achieving this goal may be through the use of modern computer modeling techniques, based on cascaded fuzzy neural networks.

It is now recognized that the development of factor models in order to technically prepare jumpers is a way of better managing the training process. In our previous studies we proposed a range of simulation models based on the analysis of video recordings of a high jump and its kinematical characteristics $[2,3]$. An interactive system that predicts the success of a high jump has been built based on these models and it allows the creation of a bespoke model for highly skilled athletes.

This software is a computer model of the high jump technique and it is based on fuzzy neural networks. Input parameters are the height of the jump and nine biomechanical quantities that are highly correlated $(\mathrm{p}<0.05)$. The system's output is the success or failure in clearing the bar: " 1 " - bar will be cleared, "-1" - it will not be cleared. By inputting the required height and other quantities we can predict if an athlete is likely to clear the bar, based on this information. The system also solves the problem in reverse; by inputting the height and the necessary result (" 1 "), we can generate the required combination to successfully make this height as output quantities.
The goal of this study was to develop a methodology for the management of technical training for high jumpers, which aims to optimally correct movements by producing a model depicting a successful high jump using the interactive prediction system.

\section{Material and methods}

Data was collected mainly using videocyclography; it recorded the kinematic motions of a high jumper as he performed competitive exercises. Two video cameras (210 frames per second and 50 frames per second) placed at two different angles to the bar were used. Reflective markers were put on the ankle, knee, hip, shoulder and elbow of the subject.

Processing and computing of the recording were achieved using Dartfish (Switzerland) video analysis software that measured 48 kinematic characteristics of 92 high jumps.

The interactive high jump success prediction system was based on the cascaded fuzzy neural network in the Medical Toolbox package [4].

An athlete was analyzed based on the available video recording of jumps performed during training and competition. The result of this exercise allowed the fine tuning of the cascaded fuzzy neural network model to record successes and failures. It included technical preparedness quantities obtained through the analysis of jumps performed in competition and training. Thus, forecasting the result, we predicted a combination of certain values. A change in one should trigger change in a host of other values and it is accomplished through this model 
(an example of this is presented in Figures 1 and 2).

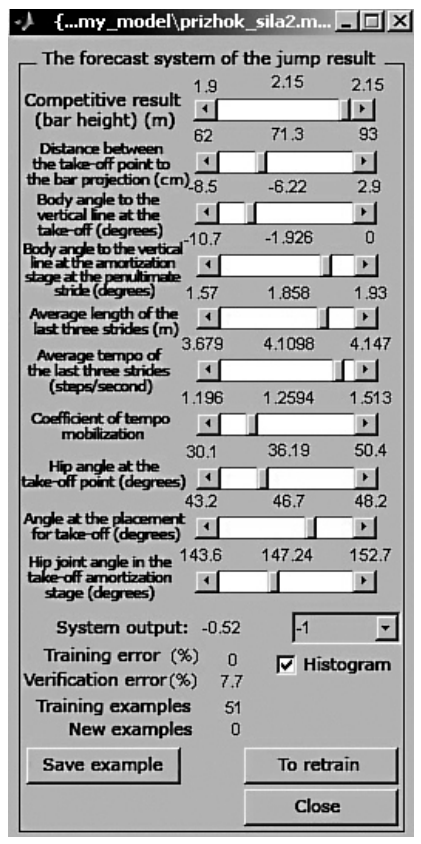

Figure 1. A screenshot of the system for prediction the outcome of a jump

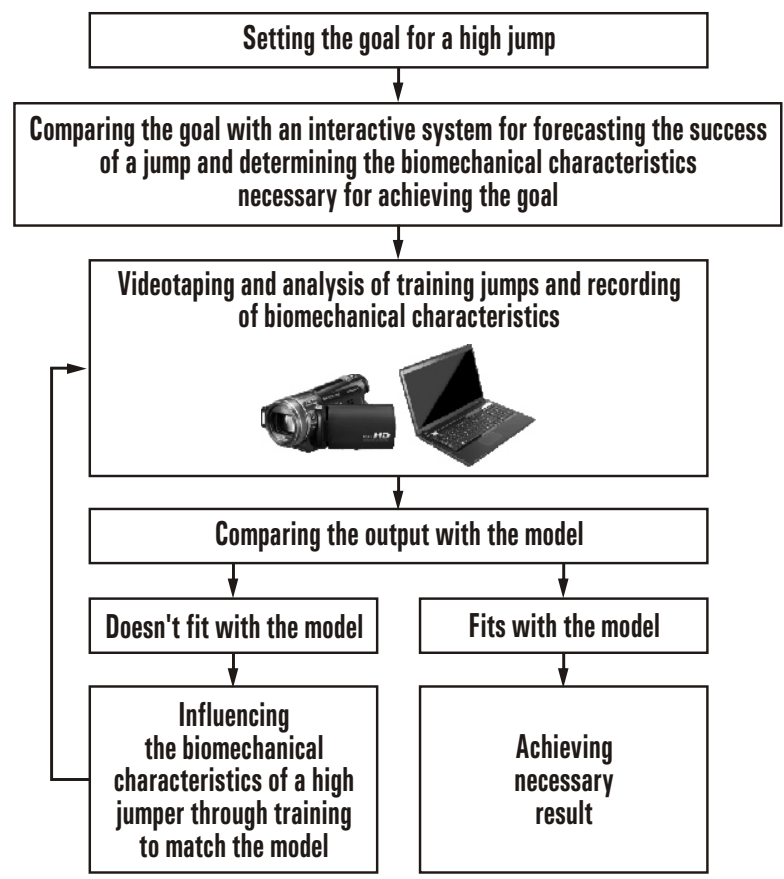

Figure 2. Use of interactive system for prediction the success of a jump in technical training of an athlete

\section{Discussion}

Interactive system for prediction the outcome of a high jump not only allows prediction but, through modification of input values, the modeling of conditions that will result in a suc- cessful jump. As a result both coach and athlete receive an "ideal" jump model for any given height with concrete values for kinematic characteristics. Analysis of video recordings of many jumps allowed the deviation of real model characteristics to be determined; based on this it became possible to design a training program that included means for correcting biomechanical quantities to bring them closer to the model.

The individual model that we created for a specific athlete included the height of the jump and nine biomechanical characteristics that were highly correlated with it $(p<0.05)$ and influenced the success of a jump at a given height. We suggest the following modifications in the training process in order to correct them (Tab. 1).

Table 1. Biomechanical quantities that can be modified during training

\begin{tabular}{|c|c|c|}
\hline & Characteristics, unit of measurement & Training modifications \\
\hline 1. & $\begin{array}{l}\text { Distance between the take-off point } \\
\text { to the bar projection, } \mathrm{cm}\end{array}$ & - Move the take-off mark \\
\hline 2. & $\begin{array}{l}\text { Body angle to the vertical line } \\
\text { at the take-off, degrees }\end{array}$ & $\begin{array}{l}\text { - Running jump to the basketball } \\
\text { hoop from various distances } \\
\text { - Running jump to the bar }\end{array}$ \\
\hline 3. & $\begin{array}{l}\text { Body angle (sagittal plane) to the } \\
\text { vertical line at the amortization } \\
\text { stage at the penultimate stride, } \\
\text { degrees }\end{array}$ & $\begin{array}{l}\text { - Increasing or reducing the width } \\
\text { of the approach curve }\end{array}$ \\
\hline 4. & $\begin{array}{l}\text { Average length of the last } \\
\text { three strides, } m\end{array}$ & $\begin{array}{l}\text { - Alternate foot jump with a final } \\
\text { push (several steps and take-off) } \\
\text { in } 2 \text { steps } \\
\text { - Alternate foot jump with increasing } \\
\text { intensity }\end{array}$ \\
\hline 5. & $\begin{array}{l}\text { Average tempo of the last three } \\
\text { strides, steps/second }\end{array}$ & \multirow{2}{*}{$\begin{array}{l}\text { - Point-to-point run with varying } \\
\text { distances between points } \\
\text { - High jumps with running approach } \\
\text { on marks (keeping the amplitude } \\
\text { of a movement) }\end{array}$} \\
\hline 6. & $\begin{array}{l}\text { Coefficient of tempo mobilization } \\
\text { (Last stride tempo/3rd stride tempo) }\end{array}$ & \\
\hline 7. & $\begin{array}{l}\text { Hip angle at the take-off point, } \\
\text { degrees }\end{array}$ & \multirow{3}{*}{$\begin{array}{l}\text { - High jumps with take-off from } \\
\text { an elevated point }(15-20 \mathrm{~cm}) \text {. } \\
\text { - High jumps with an elevated point } \\
(15-20 \mathrm{~cm}) \text { at the penultimate } \\
\text { stride }\end{array}$} \\
\hline 8. & $\begin{array}{l}\text { Angle at the placement for take-off, } \\
\text { degrees }\end{array}$ & \\
\hline 9. & $\begin{array}{l}\text { Hip joint angle in the take-off } \\
\text { amortization stage, degrees }\end{array}$ & \\
\hline
\end{tabular}

Example of the corrective technical training drills Goal: clearing a $2.15 \mathrm{~m}$ bar

Having analyzed video recordings of a series of jumps by an athlete who could not clear a $2.15 \mathrm{~m}$ bar, we determined the parameters for the biomechanical characteristics of the jumper at the time. Having compared these results with a successful jump output, predicted by the software, we found that, in order to clear the bar, Body angle to the vertical line at the take-off had to be decreased by 4 degrees, Body angle to the vertical line at the amortization stage at the penultimate stride had to be reduced by 
5 degrees and, finally, Average tempo of the last three strides had to be increased by 0.07 steps/second. The following training drill was developed:

1. Warm-up run $-1 \mathrm{~km}$. General warm-up exercises $-20 \mathrm{~min}$. Running exercises $8 \times 40 \mathrm{~m}$.

2. Alternate foot jump with increasing intensity $-4 \times 40 \mathrm{~m}$. A requirement: "Do not make steps more frequent, keep the amplitude".

3. Alternate foot jump with a final push (several steps and a take-off) in 3 steps $-5 \times 20 \mathrm{~m}$.

4. Running jump to the basketball hoop from various distances with a gradual increase in proximity of the takeoff point and the starting point to the hoop-8 times.

5. A run with a run-up without take-off with an increased approach curve -5 times.

A requirement: "Keep the body straight; do not lean into the curve".

6. Take-offs to the bar with a full run-up (8-11 running steps) with an increased approach curve -5 times.

7. Running high jump (8-11 running steps) - flop-15 times.

8. A run $2 \times 100 \mathrm{~m}$ (80\% of maximum). Relaxation and flexibility exercises $-10 \mathrm{~min}$.

Corrective exercises have to be done before a running high jump. These attempts are videotaped and further analyzed to determine changes in targeted characteristics and their comparison to the model. Figure 2 demonstrates the use of the interactive prediction system in a jumper's technical training.

It is important to note that, when working with models built on fuzzy neural networks, real characteristics can be matched with the model and the opportunity arises to tweak model characteristics because the software's structure allows the same result to be achieved using different combinations of these parameters. We can therefore mitigate the correction of biomechanical features that are difficult to change through training.

\section{Conclusions}

The interactive system that we have developed to predict the success of a jump based on the analysis of a high jump's kinematic characteristics allows the development of individual models for high-class athletes. By using this instrument to take into account all of an athlete's individual biomechanical jumping style features, we can analyze all stages of a jump in detail, improve technique through targeted correction of certain motions, and achieve the optimal combination of kinematic values for the best possible result.

A feature of our interactive prediction system training management method is in its ability to focus on the individual style of a particular athlete's movements. The method ensures an increase in reproducibility of successful jumps of any given height by stabilizing key kinematic characteristics matched by the model.

\section{Literature}

1. Lysenko, V.V. \& Romanov D.A. (2004). Managing the technical preparation of high-skill athletes based on computer video analysis of movements. Teorija i Praktika Fizicheskoj Kul'tury: Trener (an insert) 8, 30-31. [in Russian]

2. Krivetskiy, I.Y., Popov G.I. \& Bezrukov N.S. (2011). Modelling the success of motions in high jumps. Informatika i Sistemy Upravlenija 2, 126-132. [in Russian]

3. Krivetskiy, I.Y., Popov G.I. \& Bezrukov N.S. (2011). Optimization the training process of high jumpers with using the individual model of technique of jump based on a cascaded fuzzy neural network. Scientific Report Series Physical Education and Sport 15, 31-35.

4. Bezrukov, N.S., Eremin E.L., Ermakova E.V., Kolosov V.P. \& Perelman J.M. (2006). Automated system "Medical Toolbox" for diagnosing bronchial asthma using rheoencephalography results. Informatika i Sistemy Upravlenija 1, 73-80. [in Russian]

Submitted: October 9, 2012

Accepted: December 12, 2012 